University of Nebraska - Lincoln

DigitalCommons@University of Nebraska - Lincoln

Faculty Publications, Department of Psychology

Psychology, Department of

November 2003

\title{
The "sexually abused child": Potential mechanisms of adverse influences of such a label
}

\author{
Gabriel Holguin \\ University of Nebraska-Lincoln \\ David J. Hansen \\ Univertsity of Nebraska-Lincoln, dhansen1@unl.edu
}

Follow this and additional works at: https://digitalcommons.unl.edu/psychfacpub

Part of the Psychiatry and Psychology Commons

Holguin, Gabriel and Hansen, David J., "The "sexually abused child": Potential mechanisms of adverse influences of such a label" (2003). Faculty Publications, Department of Psychology. 27.

https://digitalcommons.unl.edu/psychfacpub/27

This Article is brought to you for free and open access by the Psychology, Department of at DigitalCommons@University of Nebraska - Lincoln. It has been accepted for inclusion in Faculty Publications, Department of Psychology by an authorized administrator of DigitalCommons@University of Nebraska - Lincoln. 


\title{
The "sexually abused child": Potential mechanisms of adverse influences of such a label
}

\author{
Gabriel Holguin and David J. Hansen \\ Department of Psychology \\ University of Nebraska-Lincoln
}

Submitted August 2001; accepted September 2001;

published online November 2002; published in print November 2003.

\section{Abstract}

Labeling and the effects of labeling have been extensively researched in the psychological literature in a variety of different contexts. For example, labeling has been empirically shown to lead to lowered expectancies of behavior and achievement, which can then contribute to the potential for the occurrence of a self-fulfilling prophecy with adverse consequences. Another area that has been extensively researched, with a dramatic increase in the literature base in recent history, is that of child sexual abuse (CSA). Despite various shortcomings of the research literature, the consistent findings have been identification of a variety of negative correlates and symptomatologies associated with CSA. In addition to any direct, negative effects of CSA, there may also be an additional impact from the "label" itself. Although the literature pertaining to CSA and labeling runs deep independently, efforts at addressing the issue of CSA within a labeling contextual framework have been minimal. To that end, this article examines hypothesized mechanisms of how the "sexual abuse" label may potentially have an adverse influence on the children subjected to such a label. The implications of an analysis, which addresses childhood sexual abuse from such a theoretical framework, may be a broader and more holistic understanding of the complexities and sequelae associated with CSA.

Keywords: Child sexual abuse; Labeling; Self-fulfilling prophecy

Published in Aggression and Violent Behavior 8:6 (November-December 2003), pp. 645-670. doi:10.1016/S1359-1789(02)00101-5 Copyright (C) 2002 Elsevier Science

Ltd. Used by permission. 


\section{Introduction}

Child sexual abuse (CSA) is a growing, serious, social problem in the United States. Given its extent and severity, CSA has received substantial coverage and attention over the last 20 years by the media, mental health care professionals, law enforcement personnel, the lay public, the legislature, and the judiciary. Although the term "child sexual abuse" is undoubtedly heard frequently in our culture within a variety of different contexts, no universal criteria for defining CSA has yet to be accepted (Hansen et al., 1998, Hecht \& Hansen, 1999 and Wolfe \& Birt, 1997). Most definitions of CSA, however, have specific sexual behaviors between a child and/ or adolescent and a significantly older person as defining characteristics (Browne \& Finkelhor, 1986a, Faller, 1993 and Wolfe \& Birt, 1997). With regard to the age component, most definitions characterize sexual abuse as sexual activity between a "child" (e.g., under 17) and older persons (usually defined as five or more years older than the child) (Hansen et al., 1998). CSA refers to a broad range of sexual activity ranging from noncontact offenses (e.g., genital exposure, voyeurism, and showing a child pornographic material) to intense contact offenses (e.g., genital manipulation, penile penetration, and oral sex) (Hansen et al., 1998 and Hecht \& Hansen, 1999). Another component pertaining to the definition of CSA is whether the perpetrator is related to the child. If the perpetrator is a family member, the abuse is considered intrafamilial CSA; if the perpetrator is not a family member, it is then defined as extrafamilial CSA.

Such increase in awareness of CSA has resulted in an elevating number of identified CSA cases being brought to the attention of mental health and legal professionals. In the Third National Incidence Study of Child Abuse and Neglect, the most comprehensive study of the incidence of child maltreatment to date, it was estimated in 1993 that approximately 217,700 children nationwide were known to have experienced harm from sexual abuse (National Center on Child Abuse and Neglect, 1996). Child protective service agencies in the United States reported that in 1998, 1.6 children per 1000 children experienced sexual abuse, with approximately $75 \%$ involving girls as victims (United States Department of Health and Human Services, 2000). Estimates of incidence, however, are commonly believed to be inaccurate portrayals of the true picture of CSA occurrence given that they only reflect those cases that are known to authorities. Thus, the estimates are believed to largely underestimate the true occurrence, and that many CSA cases still go unreported (Leventhal, 1998). This increased attention and awareness of CSA has acted as a catalyst for a dramatic increase of research focused on different aspects of CSA.

Although the empirical literature on CSA is characterized by various shortcomings and methodological limitations, the prevailing conclusions reached in the clinical literature have been that of negative correlates and symptomatologies associated with childhood sexual abuse (e.g., Beitchman et al., 1991, Beitchman et al., 1992, Browne \& Finkelhor, 1986a, Kendall-Tackett et al., 1993, Polusny \& Follette, 1995, Rind et al., 1998 and Tong et al., 1987). Although children may experience a myriad of different traumatic experiences growing up, none seems to be as highly and consistently associated with subsequent negative consequences as does being sexually abused. Given the significant prevalence and salience of CSA and the heightened at- tention it has received in recent history, "sexual abuse" has become an often-heard term in our society, and one that is loaded with connotations and expectations. The frequent and intense attention placed on CSA has fostered the production of a labeling phenomenon for the term "sexual abuse," which has been characterized as "a powerful and emotionally laden label" (Bromfield et al., 1988).

Given the potential for "sexual abuse" to function as a label, the variety of individuals who come in contact with children who have been sexually abused may be subject to altering their expectations and/or manner of interacting with the child based solely on the label. Children who have been identified as sexually abused usually experience a system of intervention(s) characterized by contact (e.g., interviews, therapy, etc.) with a number of adults. In addition to contact with teachers and parents, children who have been identified as sexually abused often come into contact with counselors, psychologists, investigators, social workers, nurses, doctors, and lawyers. Concern for the abused child in these circumstances is created by the notion that the expectation of negative consequences of CSA may possibly have iatrogenic potential (Browne \& Finkelhor, 1986), together with the fact that there is an existing, albeit preliminary, literature base suggesting that "sexual abuse" functions as a label resulting in a perceiver bias and subsequent overestimation in negative expectancies (e.g., (Briggs et al., 1995, Briggs et al., 1994 and Bromfield et al., 1988). The sexually abused child's extensive interaction with a wide array of adults may be providing a big dose of negative expectancies, which in turn may be fostering an environment with iatrogenic potential.

CSA is clearly an important societal problem in need of further understanding. In addition to any direct, negative effects of CSA there may also be an additional impact from the label itself. This article examines hypothesized mechanisms of how the sexual abuse label may potentially have an adverse influence on the children identified as sexually abused. An analysis, which addresses childhood sexual abuse from such a framework, will hopefully result in a broader and more holistic contextual understanding of CSA. The varied correlates that have been demonstrated to be associated with CSA will be briefly reviewed in order to provide a background for understanding possible labeling influences. Labeling research from a variety of different areas will be addressed, including educational and mental illness labels, with the discussion then focusing on research pertaining specifically to the sexual abuse label. A working model of the sexual abuse labeling process will be presented. Lastly, directions for future research and practice are addressed.

\section{Varied correlates of CSA: overview and methodological challenges}

The manner in which CSA is manifested makes research in this area quite challenging. For example, an obvious and most basic research issue is that the occurrence of a sexually abusive experience is not something that one can manipulate as an independent variable. Given limitations with respect to experimental control, a deeper and more comprehensive understanding of a variety of issues related to CSA (e.g., short- and long-term sequelae) is challenged. A causal relationship or direct association between CSA and the myriad of possible negative symptom- 
atologies frequently cited in the literature must be inferred, given the correlational nature and methodological limitations of research in this area (e.g., Beitchman et al., 1991, Beitchman et al., 1992, Browne \& Finkelhor, 1986a, Kendall-Tackett et al., 1993, Polusny \& Follette, 1995 and Tong et al., 1987).

Another related methodological limitation in the CSA research is the presence of various confounding variables that limit conclusions that can be drawn about the link between psychological maladjustment and CSA (Hecht \& Hansen, 1999, Hecht \& Hansen, 2001, Pope \& Hudson, 1995 and Rind \& Tromovitch, 1997). The association between CSA and maladjustment is not as clear when potential confounding variables such as physical abuse, emotional neglect, psychological abuse, poverty, marital dysfunction and violence, and general family dysfunction have been statistically controlled (e.g., Fromuth, 1986, Harter et al., 1988, Higgins \& McCabe, 1994 and Nash et al., 1993). In fact, (Pope \& Hudson, 1995) argue that many of the studies in the literature "are so severely vulnerable to selection bias, information bias, and lack of consideration of confounding variables that they are rendered almost valueless" (p. 378).

Despite such limitations and the complexity of the issue, the research base investigating the correlates of CSA is substantial, with many common findings of negative symptomatologies associated with CSA. In regards to the initial sequelae associated with CSA, empirical studies and numerous literature reviews have suggested that CSA is associated with a wide range of psychological problems, including fear, anxiety, depression, anger and hostility, aggression, sexually inappropriate behavior, self-destructive behavior, poor self-esteem, suicidal ideation, behavior problems, posttraumatic stress disorder, somatization, delinquency, and feelings of isolation and stigma (e.g., Bauserman \& Rind, 1997, Browne \& Finkelhor, 1986, Hecht \& Hansen, 1999, Kendall-Tackett et al., 1993 and Rind \& Tromovitch, 1997). No one symptom, however, characterizes a majority of children who have been sexually abused and/or is found universally in victims Browne \& Finkelhor, 1986a, Browne \& Finkelhor, 1986b and Faller, 1993]. In addition, it is important to note that between $33 \%$ and $50 \%$ of children who have been abused sexually have been found to be asymptomatic (Beutler et al., 1994 and Kendall-Tackett et al., 1993). Furthermore, an accumulating empirical literature base has indicated the impact of sexual abuse may be mediated and highly associated with family functioning, parenting variables, and community support (e.g., Hecht \& Hansen, 2001, Nash et al., 1993, Oates et al., 1994, Pelletier \& Handy, 1986 and Sedlar et al., 1999). Nonetheless, reviews examining the initial correlates of childhood sexual abuse have continuously demonstrated that children who have been abused sexually had more of the aforementioned presenting symptoms than children without a sexually abusive history (e.g., Kendall-Tackett et al., 1993 and Wolfe \& Birt, 1997).

As is the case with research investigating the initial correlates of CSA, recent years have seen an increase in the research investigating the long-term correlates of CSA Polusny \& Follette, 1995. Various studies investigating both nonclinical and clinical samples have reported an association between sexually abusive experiences occurring during childhood and/or adolescence and subsequent negative adult outcomes (e.g., Beitchman et al., 1992, Fromuth \& Burkhart, 1989 and Polusny \&
Follette, 1995). Taken as a whole, the evidence suggests that individuals who were abused sexually during childhood and/or adolescence report higher levels of general psychological distress and higher rates of both psychological disorders and personality disorders than nonabused subjects (Polusny \& Follette, 1995). Specifically, commonly identified long-term correlates of CSA include depression, anxiety, selfdestructive and/or suicidal behaviors, social isolation, poor sexual adjustment and dysfunction, substance abuse, binge eating, somatization, and an increased risk of revictimization, among others (e.g., (Beitchman et al., 1992, Briere, 1992, Browne \& Finkelhor, 1986, Browne \& Finkelhor, 1986, Polusny \& Follette, 1995 and Rind \& Tromovitch, 1997). Again, it is important to highlight the previously mentioned methodological limitations of research in this area (e.g., inability to deduce causality from correlational findings, presence of numerous confounding variables over time, etc.), which make elucidation of the long-term sequelae of CSA quite challenging. With that caveat mentioned, research regarding the correlates of CSA has been rigorously undertaken in recent years with many investigations supporting an association between CSA and a myriad of negative long-term sequelae.

\section{Research on labeling: examples from other contexts}

Labeling and interpersonal expectancies resulting from certain labels have been extensively researched in the social psychology and related literatures. Labeling has been empirically shown to have the potential to lead to lowered expectancies of behavior and achievement, which could then come to serve as a self-fulfilling prophecy (Rosenthal \& Jacobson, 1968). This area of research has been applied in a variety of settings and contexts, most notably in the areas of education and mental illness.

3.1. Labeling and interpersonal expectations in the classroom: the "Pygmalion effect"

Sociologist Robert Merton first identified the phenomenon known as the "self-fulfilling prophecy" in 1948. Merton used the term to describe how false beliefs about individuals and situations can often times become true (Merton, 1948). It was not until (Rosenthal \& Jacobson, 1968) controversial and classic empirical demonstration that teacher expectations could have an influence on the achievement of students that this became a heavily researched area in the field of social psychology (Madon et al., 1997). With passage of time, the term "Pygmalion effect" came to be used in the field of education to describe the importance of expectancies and their potential to influence subsequent classroom and academic achievement (Jenner, 1990). The main conclusion reached by (Rosenthal \& Jacobson, 1968) was that one person's expectations (i.e., the teacher's) for another's behavior (i.e., the students' achievement) could in essence influence the students' performance in such a manner that it fulfills the expectations, thus, creating a self-fulfilling prophecy. These findings acted as a catalyst for the investigation of educational "labels" and the potential influences they may have on the achievement and behavior of children in the classroom. Most of the early studies investigating self-fulfilling prophecies were done using experimental designs in which teacher expectations were manipulated and a target behavior was assessed. Such experiments demonstrated that the self-fulfilling proph- 
ecy could be a real phenomenon (Madon et al., 1997). (Rosenthal \& Rubin, 1978) review of the empirical literature of the first 345 studies showed that self-fulfilling prophecies do occur when teacher expectations are manipulated. Nonetheless, the notion that self-fulfilling prophecies really exist was quite controversial in the beginning stages of research in the area. The self-fulfilling prophecy, however, was later firmly established by the large number of experimental studies that consistently verified its existence (Madon et al., 1997). However, there were limitations to the experimental studies that were undertaken. For example, experimental studies only have the ability to show that perceiver expectations have the potential to lead to self-fulfilling prophecies (Jussim, 1989 and Jussim, 1993). Whether the perceivers developed false expectations naturally and whether self-fulfilling prophecies typically resulted from these false expectations was beyond the scope of what could be addressed by the experimental paradigm (Madon et al., 1997). This led many researchers to investigate self-fulfilling prophecies using naturalistic studies. Results from this line of studies concurred with the experimental evidence. These studies showed not only that selffulfilling prophecies can occur in the classroom, but also that in fact they do occur (Kolb \& Jussim, 1994). Literature reviews of the naturalistic studies (e.g., Brophy \& Good, 1974, Eccles \& Wigfield, 1985, Jussim \& Eccles, 1995 and Snyder \& Stukas, 1999) showed that teachers naturally develop erroneous beliefs and expectations regarding their students and that these expectations influence their students' subsequent achievement and behavior. In fact, expectancy effects have been shown to continue for multiple years, even in situations where teachers have considerable objective information about the students (Smith et al., 1999). Although the studies that have demonstrated that teacher expectancies influence students' academic performance have not been without criticism (e.g., Elashoff \& Snow, 1970, Jensen, 1980, Snyder \& Stukas, 1999 and Thorndike, 1968), the abundance of empirical literature showing that self-fulfilling prophecies do occur in the classroom is substantial. It is readily apparent that teachers' low, and often times erroneous, expectations can create an environment that fosters students to adhere to these erroneous beliefs.

\subsection{Outcomes of labeling children beyond the classroom}

There has been much concern regarding the negative effects associated with the assignment of diagnostic labels to children for emotional and behavioral disorders (Mash \& Terdal, 1997). In addition to the line of research that has investigated and suggested the negative influence that educational labels may have on academic performance of children in the classroom, outcomes of labeling children with diagnostic labels has also been undertaken. Much of the concern regarding the diagnostic labeling of children stems from the classic work of (Langer \& Abelson, 1974), which illustrated the effects that diagnostic labeling can have on the perceptions of and prognosis for the labeled individuals.

Yates et al., 1978 tested the possibility that memory regarding certain behaviors can be negatively influenced and/or distorted by a diagnostic label of "behaviorally disturbed." The effects of the label on observers' memory of both desirable and undesirable behaviors were examined by comparing observers' memory of the frequencies at which the behaviors occurred to the frequencies that they themselves had recorded previously for the same behaviors. The effects of labeling children with such a label was illustrated by the study in that observers overestimated the frequencies at which "behaviorally disturbed" children emitted negative behaviors. The study suggested that there was a significant interaction of diagnostic labels and the type of behavior recalled.

Foster et al., 1975 investigated the effects that labeling a child as "emotionally disturbed" has on the expectations that others hold for them. Furthermore, they examined the extent to which these attitudes are maintained in the face of conflicting evidence. The same video clip of a child was shown to all participants, with half of them being instructed that the child was considered "normal" and the other half being told that the child had been labeled emotionally disturbed by an evaluation team. Results suggested that participants rated the child more negatively when labeled as "emotionally disturbed" than when labeled "normal." Results suggest the presence of preconceived stereotypical expectancies about the behavior of children when labeled "emotionally disturbed." In addition, the researchers suggest that labeling the child as emotionally disturbed calls forth these biases, which are held even in the presence of conflicting behavior. Such a process regarding the bias phenomenon runs the likelihood that others will interact with the labeled child in ways consistent with the bias. If the child responds to the bias, the expectations held by others may be reinforced, which then has the potential to lead to a series of positive feedback loops with iatrogenic potential (Foster et al., 1975).

Studies have also shown that labeling alters the way others interact with a child who has been given a certain diagnostic label. For example, Stevens-Long, 1973 has shown that a behavior, if believed to be exhibited by a child who is "emotionally disturbed," leads to different reactions from adults than when the same exact behavior is exhibited by a child who is not labeled as such. In addition, labeling a child as "mentally retarded" was shown to lead to a lowered degree of continued motivation and persistence when the labeled child was confronted with a difficult puzzle task (Bromfield et al., 1986). These results were evident despite the fact that the child labeled as mentally retarded was rated higher in puzzle ability than her unlabeled counterpart. Such a finding is disconcerting with respect to the labeling of children given that it has the potential to condone and/or foster learned helplessness.

In sum, studies have attempted to examine the effects that certain diagnostic labels have on children subjected to such labels. Studies have shown that diagnostic labels such as "emotionally disturbed," "behaviorally disturbed," or "mentally retarded" have the potential to lead to negative effects resulting from how others perceive and react to the children. In addition to the potential negative effects resulting from how others interact with the labeled child, the label has the potential to directly influence the labeled children's perceptions of themselves and their behavior. Consistent with this hypothesis is the notion that the child who is subjected to the label comes to perceive him/herself as worth less than before being labeled. This negative perception of themselves is then internalized, which has the potential to negatively influence their behavior (Guskin et al., 1975). Thus, labeling children can have the potential to lead to negative outcomes both by how others respond to the label as well as to how the label directly impacts the child's own perceptions and behaviors. 
3.3. Negative labeling effects and chronic mental illness

Perhaps the most adversely affected by the labeling phenomenon are individuals with chronic mental illnesses. There is possibly nothing more widely recognized as stigmatizing than being labeled as "crazy" or "mentally ill." Regarding the labeling of individuals with mental illness, many have strongly advocated the adverse consequences of labeling, whereas critics have viewed labeling the "mentally ill" as a beneficial occurrence (Link \& Phelan, 1999 and Link \& Phelan, 1999). These polar perspectives concerning the labeling phenomenon as it related to mental illness spurred a heated debate. On the one hand, labeling the mentally ill is viewed as having pervasive negative consequences for psychological and social functioning given that the label is a prime determinant of the experiences of people who are so identified. For example, Scheff, 1966 argued that labeling an individual as "mentally ill" sets in place a set of negative expectations and perceptions that eventually results in a pattern of dysfunctional behaviors that conforms to the sociocultural stereotypes associated with being mentally ill. On the other hand, others viewed labeling as positive in that it ushers people into treatment so that they can get the services they need and require (Link \& Phelan, 1999 and Link \& Phelan, 1999). For example, Gove, 1975, Gove, 1980 and Gove, 1982 argued that the consequences of labeling are undoubtedly beneficial in that, rather than leading to a stabilized pattern of mental illness, being labeled as "mentally ill" opens up the door for treatment that ameliorates the symptoms. Furthermore, he argued that the symptomatic behaviors manifested by individuals labeled as "mentally ill," not social contingency, is the biggest determinant characterizing the experiences of such individuals.

Although the argument and evidence as to the potential benefits of labeling the mentally ill is acknowledged, this current discussion will focus on the literature describing the negative aspects of labeling this population due to the fact that this review addresses the potential adverse effects of the "sexual abuse" label. The focus on labeling and mental illness is warranted as it provides important empirical background for discussing labeling in relation to CSA.

There is substantial literature suggesting that adults possess negative views about individuals labeled as mentally ill and associate a host of negative characteristics with such a label (e.g., Farina \& Ring, 1965, Fink \& Tasman, 1992 and Olmstead \& Durham, 1976). Although the majority of research examining people's views about the "mentally ill" have been undertaken with the use of adult samples, children also have been shown to hold more overall negative attitudes about adults labeled mentally ill than about those designated as physically disabled or nondisabled (Adler \& Wahl, 1998). Thus, it is clear that the stigma associated with being labeled mentally ill is pervasive across the broad spectrum of individuals comprising the population of today's society. Further, the claim that it is only the deviant behavior correlated with mental illness that leads to rejection and stigma, and not labeling per se, has been refuted by numerous empirical investigations (Link \& Phelan, 1999a). In fact, studies show that the label "creates" behaviors that lead to rejection (e.g., Farina et al., 1968 and Sibicky \& Dovidio, 1986).

An explanation has been offered that identifies a mechanism through which patients' attitudes about stigma may strongly effect their quality of life (Link, 1987 and Link et al., 1989). This theory contends that the conceptions of being "mentally ill" are quite negative among the general and psychiatric population alike. Therefore, a patient with mental illness possessed these negative beliefs about mental illness before they were ever hospitalized; however, these beliefs take on a heightened relevance when an individual becomes a psychiatric patient for the first time. Now a patient transforms beliefs about rejection and discrimination into personal expectations, which ultimately alter his/her ability to function (e.g., social isolation). From this perspective, labeling can exacerbate the effects that direct negative reactions from others may pose. This paradigm emphasizes that people's internalization of negative stereotypes and expectations results in labeling effects adversely influencing the quality of life for these individuals.

Link, 1987 empirically tested this explanation. A 12-item scale was constructed which measured the extent to which a person believes that individuals identified as being mentally ill will be devalued. Participants included both patients with mental illness and nonpatients. Results showed that the degree to which a person expects to be rejected is associated with demoralization, income loss, and unemployment in individuals labeled mentally ill but not in unlabeled individuals. Thus, results supported the notion that labeling activates beliefs that lead to negative consequences (e.g., rejection, demoralization, and stigma). Further research by Link et al., 1989 also supported the notion that the stigma of mental illness labeling activates expectations of rejection.

Such labeling effects can be complex. For example, Pain \& Sharpley, 1989 found that varying the order in which positive and negative information is presented affects counselor ratings of the mental health of hypothetical clients. Presentation of "bad" (i.e., suggesting need for psychological help) information adversely influenced subsequent ratings of "good" (i.e., describing client as well adjusted) information. Practicing counselors were more affected by the negative information than counseling students.

In an exploration of the impact of self-labeling, George et al., 1999 found that college students of alcoholic parentage were more likely to label themselves as "codependent." In addition, for young adults with and without alcoholic parentage, self-labeling as codependent was associated with more symptoms. George et al., 1999 interpreted the results as suggesting that self-labeling may "fuel" pathology.

More recent work has investigated the reported experiences of rejection rather than merely expectations of rejection for persons with chronic mental illness. Rejection experiences were found to be prevalent, especially via minor insults and slights (Link et al., 1997). Although one may argue that seemingly minor insults may be inconsequential, the context of cultural stereotypes that people with mental illness frequently internalize may potentially elicit powerful and negative reactions (Link \& Phelan, 1999). In sum, although individuals that are labeled as "mentally ill" can benefit from receiving treatment, they are also subjected to a label inundated with stigma, which only serves to alienate others from them and vice versa. Research undoubtedly supports the notion that labeling the "mentally ill" results in adverse and debilitating consequences regarding psychological, emotional, and/or behavioral functioning. 


\section{Research on the influence of "sexual abuse" as a label}

A child who has been abused sexually is often referred to as a "sexually abused child" or a "sexual abuse victim." Referring to the child as such is necessary given that it correctly describes the experience that the child has undergone and is needed for child protection, evaluation, intervention, etc. Yet, the automatic use of such a reference also facilitates its functioning as a label with impact beyond its original intent. For example, DeRoma et al., 1997 found that, despite all other behavioral characteristics being held constant, the label of child "physical abuse" negatively influenced ratings of adjustment and prognosis by social service and clinical psychology professionals.

It would be erroneous to attempt to understand the implications and correlates associated with CSA without addressing the social context and network in which these children engage. Given that there is a widely recognizable literature base suggesting that family functioning and parenting variables play an important role in the possible mediation of the correlates of sexual abuse (e.g., Nash et al., 1993, Oates et al., 1994, Pelletier \& Handy, 1986 and Stern et al., 1995), it is important to address the effects that being labeled as sexually abused may have on family relations.

\subsection{Potential effects of the sexual abuse label on family relations}

Given the stigmatizing impact that labeling within the context of education and mental illness has been shown to have on interpersonal relationships, children who are identified as sexually abused may be similarly negatively affected by such a label (Briggs et al., 1994). If positive family functioning and parenting variables can serve as protective factors mediating the adverse "effects" of CSA, then it is rational to posit that parenting variables also have the potential to exacerbate the condition. It has been pointed out that discussions regarding family functioning and its association with the correlates of CSA are not intended to blame either families or individual family members (Hoagwood, 1990). However, if one wants to attain a greater, more comprehensive understanding of the sequelae associated with CSA, addressing the issue within the context of family functioning is of paramount importance. An occurrence as salient as CSA undoubtedly will place a burden of stress on the degree, quality, and/or characteristics of family functioning. To that end, the natural question that surfaces is: What are the potential effects that the "sexual abuse" label may have on the family relations of a family in which a child has been sexually abused?

Research suggests that adult expectations for adjustment and future behavior of maltreated children may be negatively biased, and that this may exacerbate negative outcomes for maltreated youth (e.g., DeRoma et al., 1997). This negative bias may be a direct result of the occurrence of family members, particularly parents, and others buying into a "damaged child" perspective; that a child who has been sexually abused is destined to have substantial adverse psychological, emotional, and behavioral outcomes. Browne \& Finkelhor, 1986 warn that an exaggeration of the negative consequences of CSA can have iatrogenic potential. Further, maltreated children follow different developmental pathways leading to the array of documented negative outcomes (e.g., Cicchetti \& Rogosch, 1997 and Cicchetti \& Toth, 2000).
Thus, labeling a child as "sexually abused" and using that label as a determinant dictating the type and quality of familial relationships and interactions afforded the child may act as a mechanism that fosters more adverse outcomes in children who have endured sexually abusive events or incidents. In addition, there is a literature base suggesting that parents' expectations of their children's behavior and their interactions with their children may have implications for both the immediate parental response and for the quality of family relationships over time (e.g., Azar et al., 1984, Azar \& Rohrbeck, 1986, Azar \& Wolfe, 1998, Bugental et al., 1989, Bugental et al., 1998 and Bugental \& Shennum, 1984). This further illustrates the relationship between parental expectations and the quality of subsequent parent-child and family relationships. In summary, labeling may negatively impact parental expectations of their maltreated child, resulting in an exacerbation of negative outcomes and/or place an adverse stress affecting the quality of family relationships.

\subsection{Influence of the "sexual abuse" label inside and outside of the classroom}

Does identification of a child as "sexually abused" also have the capacity to influence others' expectations and attitudes regarding that child? Can such a label, which is loaded with powerful and emotional connotations, lead to lowered expectations from others in the absence of evidence to do so? Research into the potential influences that the "sexual abuse" label may have on others is preliminary and scarce when compared to the breadth of literature addressing either CSA or labeling in general. There are several empirical studies, however, which have demonstrated that such a label leads to lowered or negative expectations and/or beliefs regarding these children (Briggs et al., 1994, Briggs et al., 1995 and Bromfield et al., 1988). Such results elucidate the importance of systematically researching the expectations adults hold for children who have been sexually abused (Briggs et al., 1994). The importance of this issue is strengthened by the fact that early social psychology and related literatures have amply demonstrated that teacher's negative expectancies can adversely influence a child's achievement and that certain diagnostic labels such as "mentally ill" have been shown to result in negative consequences for the labeled individual.

Bromfield et al., 1988 investigated the influence of the sexual abuse label on teachers' perceptions of a child's failure. Seventy-seven junior high and high school teachers participated in the study, with 51 of the subjects being male. Two identical vignettes describing a 6-year-old girl having difficulties assembling a puzzle (where she eventually gives up) were used, with the only difference between the two vignettes being that one had an added statement describing her as having been sexually abused. A $2 \times 2 \times 2 \times 2 \times 2$ (Teacher's Gender $\times$ Previous Experience with Sexually Abused Children $\times$ Junior or Senior High School Teacher $\times$ Labeled vs. Unlabeled Child $\times$ Vignette Order) design was used, with labeled vs. unlabeled as a within-subjects factor and all other variables as between-subjects factors. Although teachers rated the abused child as superiorly skilled, greater future success on tasks was attributed to the unlabeled child. Similarly, teachers reported that they would not encourage the labeled child to keep trying at tasks to the same extent as they would for the unlabeled child. The reluctance of teachers to encourage an abused child to 
persist on academic tasks (even in situations where the child can and should persist) and predictions that the abused child would achieve less future success than the unlabeled child may inadvertently foster an environment that inhibits intellectual growth. The results suggest that effects of the sexual abuse label do exist in the classroom and may adversely influence teachers' perceptions, expectations, and interactions with the child. Although the findings can at best be described as preliminary, they definitely are of importance given the extent of involvement that children have in the classroom. Moreover, future studies would benefit from the manipulation of age and gender variables when investigating the effects of the sexual abuse label.

Briggs et al., (1994) tested the hypothesis that knowledge of a child's history of sexual abuse results in adults' expectations for the child that differs from their expectations for children who have not been sexually abused. The sample consisted of 279 female undergraduate students. A $2 \times 3 \times 2$ (Acquaintance with Abuse [either abused themselves or emotionally close to someone who was abused] $\times$ Family History of Sexual Abuse [labeled abused vs. unlabeled] $\times$ Sex of Child) between-subjects design was conducted to study the effects that the sexual abuse label has on expectations for the labeled child. Children with a family history of sexual abuse were viewed by adults as having more internalizing behavior problems and less likely to achieve than children who have not been sexually abused. Furthermore, the abused children were viewed by adults as being less nice, less likely to help others, and less likely to be liked by everyone or to have friends. The results suggest that adults may develop negative stereotypes and expectations regarding sexually abused children, even when the children may not have exhibited any negative symptoms. In addition, the results found that adults expected girls labeled as sexually abused to be less likely to suffer from externalizing behavior problems than boys. Again, although these findings can at best be described as preliminary, they suggest an occurrence that has the potential to be extremely damaging to children who have been sexually abused. Despite limitations regarding generalizability of the sample used (i.e., female undergraduates), the study advanced the scarce research base on this issue.

Another empirical investigation was conducted by Briggs et al., 1995 examining whether perceiver bias influences the reactions of others to sexual abuse. Specifically, perceptions of children labeled as sexually abused were compared with perceptions of children labeled as coming from normal families and those labeled as having a mother who was dying from cancer. The investigators hypothesized that judgments regarding externalizing and internalizing problems would be greater for the children labeled as sexually abused than for those who were identified as having a mother who was dying from cancer. A second hypothesis was that the children labeled as sexually abused who exhibited less aggressive behavior would be viewed more negatively than control children who exhibited more aggressive behavior. The sample was 497 undergraduate students. The respondents were predominantly White $(86.7 \%$ ) with ages ranging from 18 to 53 years. A $2 \times 3 \times 2 \times 2$ (Respondent Gender $\times$ Family History Label of Child $\times$ Child Gender $\times$ Severity of Aggression) betweensubjects ANOVA was conducted to test the hypotheses. Children labeled as sexually abused were perceived as having significantly more externalizing and internaliz- ing behavior problems than both other groups. Furthermore, results suggested that children labeled as sexually abused who exhibited less aggressive behaviors than the control group were perceived as having more internalizing problems than that group. In addition, sexually abused girls were perceived as having more internalizing problems than daughters of mothers who were dying of cancer, whereas sexually abused boys and sons of cancer-stricken mothers did not differ significantly. Although the sample employed has limited generalizability, results of the study further elucidate the importance of investigating the potential detrimental influence of the sexual abuse label.

The literature base that does exist regarding the sexual abuse label suggests that individuals create lowered expectancies as a result of the label. Findings support the notion that children labeled as sexually abused are viewed more negatively than children without the label (e.g., Briggs et al., 1994, Briggs et al., 1995 and Bromfield et al., 1988). These biased perceptions have caused some researchers to propose that some of the negative effects of sexual abuse are maintained as a result of the negatively biased perceptions and lowered expectancies for children who have been sexually abused (Briggs et al., 1995). In addition to the maintaining of these negative effects as a result of perceiver bias and expectations, an exacerbating phenomenon may potentially be occurring as well (i.e., symptoms are increased or worsened).

\section{Potential mechanisms of influence}

When discussing the potential mechanisms of how the sexual abuse label may exert its deleterious effects, it is imperative to address the discussion within the context of the social psychology, educational, CSA, and related literatures. The diverse literatures addressing topics such as self-fulfilling prophecies, expectations, and labeling are needed to begin to understand the pathways by which the influence may be operating, while the CSA literature helps elucidate the net results. The social psychology and educational research and the CSA research should not be viewed as separate and distinct bodies of literature, but rather as complimentary adjuncts. It would be a dramatic and deleterious error to dismiss the negative symptomatology associated with CSA as the result of self-fulfilling prophecies. However, addressing the issue within the context of the potential influences of labeling may lead to a deeper, more contextual, and possibly more realistic understanding of the problem. The social psychology, educational, and related literatures and the CSA literature should not be viewed as a square peg and a round hole. Rather, combining the bodies of literature would be an asset in our continued attempts of attaining a broader and more holistic understanding of the correlates of CSA.

\subsection{Salience, vividness, and availability}

Salience refers "to the properties of a stimulus that make it likely to attract attention relative to its context" (Salovey \& Turk, 1991). Vividness refers to the inherent properties of a stimulus that attract attention independent of its context (Fiske \& Taylor, 1984). The availability heuristic refers to the tendency to judge the probability of the occurrence of an event by the ease to which it is brought to mind (Tver- 
sky \& Kahneman, 1973). All of the preceding characteristics interact to influence the forming of an initial impression. The theoretical underpinning to this notion is that some people and some features are more noticeable than others. Furthermore, it is posited that particularly salient aspects of an individual or occurrence will exert greater influential potential on judgment (Salovey \& Turk, 1991). Although the majority of this type of research has been applied to the area of clinical judgment and decision-making, it undoubtedly has relevance to this discussion regarding CSA and the potential impact of labeling. The "high publicity case" brings the many cameras and reporters of television news and print media to highlight the occurrence of CSA to the world (Elvik, 1994). Furthermore, CSA has received substantial coverage and attention over the last 20 years, from health and mental health care professionals, to law enforcement personnel, to legislators and judges, and to the media. With its prevalence and this attention, CSA has become an issue that has become increasingly apparent and salient in our society.

The high-profile CSA cases, which are usually the ones that are portrayed in the media, have powerful and influential properties. With regard to vividness, these CSA cases oftentimes portray the sullen, aloof, isolated, "perverted" stranger who brutally victimizes the child via an encounter characterized by an abduction and forced sexual activity. Undoubtedly, these are the types of cases that the news and print media most often relate to society. This type of CSA undoubtedly is not the norm, with most incidences of CSA being perpetrated by someone known to the victim (Wolfe $\&$ Birt, 1997). As a result of this societal influence, the more mundane is forgotten with the unusual being remembered (Salovey \& Turk, 1991). Given that severity of the sexually abusive situation is associated with post-abuse symptoms and their severity (Kendall-Tackett et al., 1993 and Wolfe \& Birt, 1997), these cases are more likely to result in severe and traumatic psychological consequences for the child such as posttraumatic stress disorder, high levels of anxiety and depression, regression to earlier developmental stages, and behavioral problems, among others. These characteristics of the highly publicized case (i.e., forcefulness involved and subsequent severe trauma) make it more likely that it will create a very vivid depiction in the minds of individuals. Given the aforementioned saliency and intense coverage CSA has received in our culture, it is reasonable to hypothesize that availability heuristic effects may transpire.

Thus, when individuals hear about an occurrence of CSA, it is quite possible that what comes to mind are those cases of sexual abuse that the media portrays. This, in essence, may act as a catalyst to trigger a labeling "snowball" effect. The individual may come to label the child as a "sexually abused child" or "sexual abuse victim" and expect the myriad of negative consequences that have been heavily documented in the literature and press. Adhering to these expectations and/or a thinking that the child is "damaged or affected for the rest of her (or his) life" makes it more likely that the individual will interact differently with the child. These types of interactions may be influential in that they may potentially be creating an environment ripe for the self-fulfilling prophecy phenomenon. Thus, the emotional, psychological, and behavioral problems that may manifest in a child who has experienced CSA may possibly be maintained or exacerbated by such interactions. It is important to note that this discussion is in no way implying (either intrinsically or extrinsically) that the more common CSA cases do not also have outcomes characterized by more severe and problematic emotional, behavioral, and psychological functioning in the child. Such an assertion would be a gross error. This discussion is, however, hypothesizing that automatically lowering one's expectations for a child who has been sexually abused may have the potential to activate a cascade of events with iatrogenic potential

\subsection{Expectations and self-fulfilling prophecies}

Given that little is known about moderators of naturally occurring self-fulfilling prophecies, Madon et al., 1997 studied some of the conditions under which selffulfilling prophecies might be more powerful. The results of the study demonstrated that teachers' expectations led to powerful self-fulfilling prophecies among "low achievers." Although the researchers contend, based on empirical studies, that there is mounting evidence suggesting that self-fulfilling prophecies have a small effect on average (Jussim, 1989, Jussim, 1991 and Jussim \& Eccles, 1992), they acknowledge that they can be especially powerful among certain populations, such as minorities, individuals from lower socioeconomic backgrounds, and other stigmatized groups. The direct implications for this study to CSA are illustrated by the researchers' following comments: "Nonetheless, this does not mean that naturally occurring self-fulfilling prophecies must be, or are always, small. Under certain conditions, and for certain types of targets, self-fulfilling prophecies may be more powerful than average effect sizes suggest" (Madon et al., 1997). Thus, results suggest that although self-fulfilling prophecies may often times be small, there are certain target populations that experience negative expectations in disproportionate amounts that may subject them to more powerful self-fulfilling prophecies. To that end, one can reasonably contend that children who have been sexually abused are a prime example of a population who may be affected by these more powerful self-fulfilling prophecies.

A sequential series of steps may best illustrate how the findings from the variety of literatures could possibly be joined in such a way that leads to a more comprehensive and contextual understanding of CSA. If self-fulfilling prophecies naturally occur, and if individuals experiencing CSA exhibit negative symptoms, and if adults alter their expectations for sexually abused children, then it seems rational to hypothesize that the phenomena of self-fulfilling prophecies has a legitimate place in the arena of CSA. For example, perhaps adults' lowered expectations regarding sexually abused children fosters an environment that essentially helps to "set them up" to live up to the negative expectations placed upon them. Given this, it can be rationally hypothesized that some of the adverse symptomatology exhibited by individuals experiencing CSA may come from the potential influences of the sexual abuse label. The intent is to suggest that a maintaining and exacerbating phenomenon may be occurring as a result of the residual effects of the sexual abuse label, not to deny the fact that CSA can lead to serious adverse outcomes.

\subsection{A working model to prompt research and discussion}

A working model hypothesizing how the sexual abuse label may potentially influence the child adversely is presented in Fig. 1. This model is constructed from a 


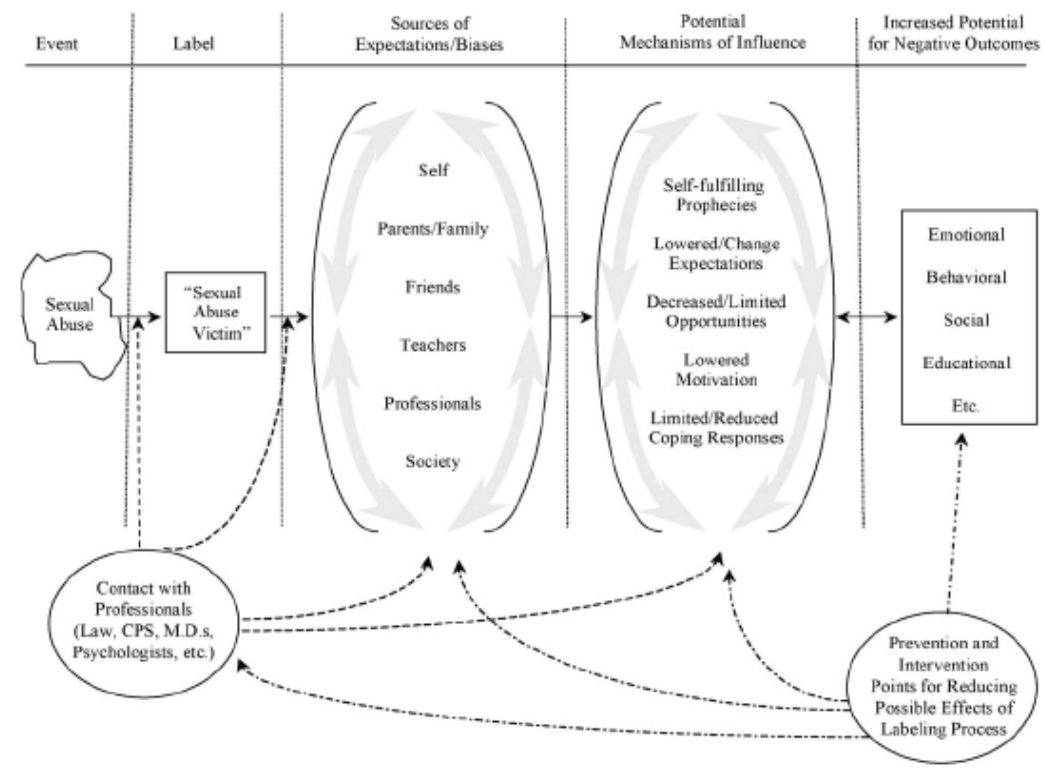

Fig. 1. Working model of the "sexual abuse" labeling process that may contribute to negative postabuse outcomes.

foundation that incorporates the deep and heavily supported areas of research pertaining independently to labeling and CSA. Preliminary studies demonstrating that the sexual abuse label negatively influences the expectations regarding the child who has been sexually abused (e.g., Briggs et al., 1994, Briggs et al., 1995 and Bromfield et al., 1988) has acted as a catalyst for its development. This working model ties concepts and theoretical underpinnings of the social psychology, educational, and related literatures regarding expectations, biases, and labeling, and proposes how such phenomena may act as influential pathways leading to an increased potential for the negative outcomes highly cited in the CSA literature.

The cascade of events commences when the sexually abusive experiences transpire and are subsequently reported and/or disclosed, usually to an adult and often to a parent (Paine \& Hansen, 2002). The allegations are subsequently reported to authorities. This usually propels the child into numerous contacts with professionals from a variety of disciplines such as police investigators, Child Protective Services personnel, medical doctors, and psychologists, among others. The sexually abusive experience(s), if substantiated by investigation, results in the child being identified as a "sexual abuse victim"; thus, interactions with the child by a host of individuals often occur with that label subtly or explicitly implied. This label then comes to serve as a basis upon which individuals develop a certain level of expectations or biases for the child who has been sexually abused. It is posited that these expectations and biases are formulated and adhered to by a wide array of individuals consisting of the child him/herself, parents and family members, peers, teachers, the variety of professionals in contact with the child, and society as a whole.

The aforementioned individuals entail a network of people with whom the child will probably come in contact and be intricately associated. The literature base suggesting that individuals develop certain expectations and biases regarding children who have been sexually abused have employed samples consisting of teachers and university undergraduate students (e.g., Briggs et al., 1994, Briggs et al., 1995 and Bromfield et al., 1988). Based on these findings, it is reasonable to hypothesize that the child's parents and family members may also have some level of expectations and biases based on their view of the child as a "sexual abuse victim." In addition, although not employing the sexual abuse label, it has been empirically demonstrated that peers like labeled children less and behave in a consistently more negative manner toward them than they do to children without a label (Milich et al., 1992), including labels such as identifying a child as being in "special behavior problem classes" (Harris et al., 1992). Furthermore, the array of professionals that the child often comes in contact with possess a set of beliefs and expectations for the child who has been sexually abused. Practical experience suggests that it is not uncommon for professionals and other adults who come in contact with the child and family to react in ways that suggest, or actually say, things such as "the child will never be the same" or "this will have terrible effects." Such reactions and statements reflect a certain expectation level and/or bias regarding these children. These expectations and biases may manifest in law enforcement personnel, social service workers, physicians, and mental health professionals such as psychologists and counselors. The pathway through which the label may exert its influence is via the expectations and biases that may be created as a result of the sexual abuse label.

This lowering or changing of expectations may influence how individuals interact with the child who has been sexually abused. For example, as noted earlier, Bromfield et al., 1988 found that teachers encouraged unlabeled children to persist on academic tasks much more than children labeled as sexually abused. Of the responders who allowed the child labeled as sexually abused to quit sooner than the unlabeled child, a majority reported a presumed vulnerability to stress as a major reason for doing so. Teachers may be reluctant to encourage a child who has been sexually abused to persist on academic tasks, even in the absence of any evidence warranting the lowered motivation. Bromfield et al., 1988 purported that teachers inadvertently may foster helplessness, which in essence hampers intellectual growth. The fostering of helplessness may also potentially hamper growth in other areas (e.g., psychological and emotional development). Further support of this notion that negative perceptions are made regarding a labeled child, even in the absence of evidence justifying such perceptions being made, comes from research suggesting that peers of a labeled child create and maintain negative impressions even in cases where the labeled child provides disconfirming evidence (Milich et al., 1992). 
It is hypothesized that it is through these lowering of expectations or creation of negative biases that children may be adversely influenced. Possessing and maintaining these negative expectations arguably will influence the manner in which individuals interact with the child labeled as sexually abused. Given that there is preliminary literature suggesting that teachers may not encourage children to persist on tasks in which they can and should persist (Bromfield et al., 1988), it is not unreasonable to contend that the myriad of other individuals that the sexually abused child interacts with may also alter the way in which they interact with the child. Their interactions with the child may in essence inadvertently decrease and/or limit the opportunities available to the child who has been sexually abused. Parents, family members, teachers, and professionals may not motivate them as much given that they possibly believe the child may not have the resources or capacity to do so as a result of their abusive experience(s). Eventually, such influences may also impact self-motivation. In addition, intense feelings of sympathy for the child may act to limit opportunities to create and/or enhance coping strategies and resiliency given that the adult may foster an environment of helplessness. Although it is important that the child who has been sexually abused possess a supportive and nurturing environment, overreacting to the perceived negative consequences of the abusive experience may create and maintain an environment ripe for the self-fulfilling prophecy.

It is through these proposed mechanisms that lowered expectations and negative biases for children who have been sexually abused may increase the potential for negative emotional, behavioral, social, educational, and other outcomes. This model proposes that such mechanisms may potentially function to maintain and/or exacerbate the negative correlates associated with CSA and may have iatrogenic potential for this population of children. It is important to note that the last two stages of this cascade of events (i.e., mechanisms of influence and an increased potential for negative outcomes) are reciprocal in nature. Thus, interactions and/or an environment characterized by limited opportunities, lowered motivation, and a reduction in coping strategies and responses increase the propensity for negative symptomatology. This exacerbation of negative symptoms in turn functions to strengthen and maintain the negative expectations and biases that led to an increased potential for negative outcomes. This reciprocal cycle in essence maintains the potential adverse influences of the sexual abuse label.

\section{Directions for future research and practice}

\subsection{New wave of research}

Before we can attempt to understand the CSA literature within a broader context and framework, there is a need to improve the existing research. Although the area of CSA witnessed an enormous growth in literature since 1986, much more needs to be done. As Polusny \& Follette, 1995 have indicated, "research in this area remains in an early phase of development" (p. 160). This need is further illustrated by the existence of contrasting findings in the CSA literature, largely stemming from methodological limitations. As Briere, 1992 suggests, future research should be characterized by "more tightly controlled and methodologically sophisticated studies" (p. 202). Future studies should use samples that have greater generalizability than typi- cal clinical populations. Furthermore, future studies should take into account the important confounding variables that are often associated with CSA when investigating sexual abuse experiences. In addition, CSA experiences need to be explored in a manner that addresses both cross-cultural and gender differences Polusny \& Follette, 1995. Generalizing findings from studies done predominantly on White girls and women to other populations is highly problematic. The importance of this notion is further strengthened given that it has been suggested that males may experience CSA differently than females (Hecht \& Hansen, 1999, Rind \& Tromovitch, 1997 and Watkins \& Bentovim, 1992). Lastly, research needs to be done on other ethnic populations due to the important role that different cultural factors may play in the understanding of CSA.

\subsection{Research associated with resilient outcomes}

Research on factors that contribute to resilient post-abuse outcomes is scarce. (O'Dell, 1997) notes how 'the positive images from survivors' life stories and the political aspects of survivorhood are totally absent from the symptomatologies that abound in the mainstream research area" (p. 336). An increase in such research is warranted given the importance of the potential information yielded. Such research would have direct implications for the development of treatment programs and in the understanding of variables related to resilient individuals (Polusny \& Follette, 1995). Research investigating resilience has direct implications in that variables associated with such outcomes can be identified and used in the development of treatment approaches for children who have been sexually abused. It has been advocated that the treatment of sexually abused children focus on themes of resilience in order to uncover strengths in the children while validating and discussing the trauma (Andersen, 1997).

\subsection{Sexual abuse label research}

Empirical evidence suggests that the sexual abuse label leads to negative stereotypes and expectations by adults regarding children who have experienced CSA (e.g., Briggs et al., 1994, Briggs et al., 1995 and Bromfield et al., 1988). Such findings are disconcerting, given the knowledge that expectations regarding these children may have the potential to lead to self-fulfilling prophecies that contribute to negative outcomes. Therefore, it is imperative that future studies continue where these initial studies have left off.

The literature available, which has specifically investigated the potential influence that the sexual abuse label has on adults' perceptions and expectations, has employed college student and teacher samples. Future research should be implemented, which assesses the expectancies of professionals (e.g., mental health professionals, child protection workers, law enforcement investigators, physicians, etc.) who work intricately and directly with the children who have been sexually abused (Briggs et al., 1995). Briggs et al., 1995 also suggested that future research that investigates the influence that the sexual abuse label may have on adult expectations should manipulate the age of the labeled child to see if the age of the victim influences adult expectancies. In addition, studies that manipulate several moderating variables (e.g., 
extent of abuse, amount of force involved, relationship to perpetrator, etc.) pertaining to the sexual abuse label are warranted.

The social psychological literature on the influence of labeling on expectations and self-fulfilling prophecies has long been challenged by the need to balance experimental control with external validity. Analog studies (e.g., using vignettes) provide greater control over possible confounds but do not have the generalizability of more naturalistic studies (Elashoff \& Snow, 1970, Jussim \& Eccles, 1995, Snyder \& Stukas, 1999 and Thorndike, 1968). Given the many challenges of studying CSA as an independent or predictor variable of interest, research on the sexual abuse label may face even greater challenges.

\subsection{Implications for interventions}

The labeling phenomenon may also have important implications for interventions related to CSA. Parental characteristics are particularly important in this discussion because of the crucial factor that parents play in the development of their children. Improving our understanding of the ways parental characteristics function as protective factors (as well as exacerbating factors) for children who have been sexually abused will likely lead to the creation or refinement of more effective treatment interventions for children subjected to such experiences. The importance of the labeling phenomenon's potential impact on parents of children who have been sexually abused is further highlighted by the notion that parental support is a pivotal element in mediating the effects of CSA (Cohen \& Mannarino, 1998 and Hansen et al., 1998). Therefore, interventions that address and acknowledge the potential adverse effects that the sexual abuse label may have on parents are warranted. Given that parental support and expectations are of paramount importance in the outcomes and subsequent development of children who have experienced sexually abusive experiences, education and awareness of the potential adverse influences of the labeling phenomenon may prove to be fruitful and beneficial components of intervention programs. Seeing, perceiving, and interacting with the child in a manner that is not characterized by lowered expectations due to the sexual abuse label may diminish a "damaged child" mentality and serve to protect the child from additional and exacerbated harm.

The aforementioned importance of the labeling phenomenon and its potential for adults to overestimate the consequences of sexual abuse for a particular child is of importance not only to the parents but also to the mental health and related professionals responsible for administering the interventions and related services. This caveat is further strengthened by the literature base suggesting that "sexual abuse" functions as a label resulting in a perceiver bias and subsequent overestimation in negative expectancies (e.g., Briggs et al., 1994, Briggs et al., 1995 and Bromfield et al., 1988). The working model proposed within this article suggests that there are various intervention points where the potential negative influences of the sexual abuse label may be ameliorated (see Fig. 1). Specifically, the professionals who come in contact to provide services and advocate for the child may benefit from an awareness of how preconceived perceptions and expectations for children who have been sexually abused may inadvertently be harmful to the child. Parents, caregivers, teachers, mental health professionals, law enforcement personnel, social service workers, and anyone possibly involved in the child's social network can be made aware of these risks so as to minimize the chances that an environment will be created and maintained that is plagued with the proposed mechanisms of influence. Such awareness will allow individuals to constantly monitor and assess the manner in how they are interacting with the child who has been sexually abused in efforts to decrease the chances that a self-fulfilling prophecy will unfold. Interventions that advocate the creation of an environment that enhances rather than limits opportunities and increases motivation so that coping and resilient responses can be created minimizes the chances that a learned helplessness will be fostered.

\subsection{Education regarding the potential detrimental influences of the "sexual abuse"} label

Children who have been identified as sexually abused usually are subjected to a system of intervention characterized by contact (e.g., interviews, therapy, etc.) with a number of adults. In addition to contact with teachers and parents, children who have been identified as sexually abused often come into contact with counselors, psychologists, investigators, social workers, nurses, doctors, and lawyers. This is an area of professional concern and future research, given what is known about false expectations leading to self-fulfilling prophecies together with evidence suggesting that adults develop adverse expectations regarding sexually abused children. Under these circumstances, it is reasonable to suggest that such an extensive intervention with a wide array of adults may possibly be giving the child a dose of negative expectancies that in turn may be fostering an environment with increased potential for negative outcomes. Therefore, those involved in work with children who have been sexually abused should be educated on how creating unmerited negative expectancies due to the sexual abuse label may possibly be detrimental to the child. Of course, research addressing such issues is needed.

\section{Conclusion}

CSA is a societal problem that has been heavily addressed throughout the literature of various disciplines. A major interest in this area has been focused on possible psychological effects resulting from such experiences (Pope \& Hudson, 1995). It has been proposed within this article that incorporation of the social psychology, educational, and related literatures regarding expectations, self-fulfilling prophecies, and labeling effects with the CSA literature may possibly result in a more complete understanding of the problem. On the surface, the various bodies of literature have yielded strongly supported findings, which seemingly appear to be distinct and unrelated. However, preliminary findings regarding the influence of the sexual abuse label on the expectancies of adults suggests that an amalgam between the bodies of literature may be in order. It can be hypothesized, based on empirical findings within the two domains, that the self-fulfilling prophecy phenomenon and/or the influence of negative expectations and biases may possibly be contributing to the negative symptoms cited in the clinical CSA literature. The sexual abuse label may increase the potential for negative outcomes by triggering various mechanisms of influence that may maintain or exacerbate negative symptomatology manifested by sexually abused children. 
A working model has been proposed, which delineates potential mechanisms of how the sexual abuse label may have an adverse influence. Given the importance of building and suggesting hypotheses on strong theoretical backgrounds, this current working model attempts to build a bridge between the various heavily investigated and supported lines of research. The diverse research literatures that address the potential influences of expectations, biases, and labeling is the foundation upon which this model is founded. The model addresses the myriad of negative symptomatologies that have been heavily documented to be associated with CSA within this labeling framework. The model examines and outlines hypothesized mechanisms of how the sexual abuse label may potentially have an adverse influence on the children subjected to such a label. Such an analysis, which addresses childhood sexual abuse from this proposed theoretical framework, may potentially result in a broader, more holistic, and accurate understanding of the sequelae associated with CSA. Furthermore, the model suggests that various intervention points along a continuum of events and outcomes may serve as a mediating factor protecting against the maintenance, exacerbation, or possible creation of negative outcomes.

Identification and labeling of a "sexually abused child" are absolutely essential for child protection, evaluation, and intervention. It would be ludicrous to suggest that CSA, in and of itself, does not have damaging influences on the adjustment of the child. As noted earlier, a growing and increasingly sophisticated body of research literature suggests that CSA is associated with a variety of negative outcomes. Is it possible that factors above and beyond the CSA experience may account for some of the negative symptomatology? Preliminary findings investigating the influence of the sexual abuse label on the expectations of adults, coupled with existing evidence regarding the impact of expectations and self-fulfilling prophecies, suggest that such an occurrence is quite possible. Further research regarding this possibility is warranted so that these children will not be further challenged by those that intend to help and support them.

\section{References}

Adler \& Wahl, 1998. A.K. Adler and O.F. Wahl, Children's beliefs about people labeled mentally ill. American Journal of Orthopsychiatry 68 (1998), pp. 321-326.

Andersen, 1997. K.M. Andersen, Uncovering survival abilities in children who have been sexually abused. Families in Society: The Journal of Contemporary Human Services 78 (1997), pp. 592-599.

Azar et al., 1984. S.T. Azar, D.R. Robinson, E. Hekimian and C.T. Twentyman, Unrealistic expectations and problem-solving ability in maltreating and comparison mothers. Journal of Consulting and Clinical Psychology 52 (1984), pp. 687-691.

Azar \& Rohrbeck, 1986. S.T. Azar and C.A. Rohrbeck, Child abuse and unrealistic expectations: Further validation of the Parent Opinion Questionnaire. Journal of Consulting and Clinical Psychology 54 (1986), pp. 867-868

Azar \& Wolfe, 1998. S.T. Azar and D.A. Wolfe, Child physical abuse and neglect. In: E.J. Mash and R.A. Barkley, Editors, Treatment of childhood disorders (2nd ed.),, Guilford, New York (1998), pp. 501-544.

Bauserman \& Rind, 1997. R. Bauserman and B. Rind, Psychological correlates of male child and adolescent sexual experiences with adults: A review of the nonclinical literature. Archives of Sexual Behavior 26 (1997), pp. 105-141.

Beitchman et al., 1991. J.H. Beitchman, K.J. Zucker, J.E. Hood, G.A. daCosta and D. Akman, A review of the short-term effects of child sexual abuse. Child Abuse and Neglect 15 (1991), pp. 537-556.
Beitchman et al., 1992. J.H. Beitchman, K.J. Zucker, J.E. Hood, G.A. daCosta, D. Akman and E. Cassavia, A review of the long-term effects of child sexual abuse. Child Abuse and Neglect 16 (1992), pp. 101-118.

Beutler et al., 1994. L.E. Beutler, R.E. Williams and H.A. Zetzer, Efficacy of treatment for victims of child sexual abuse. Future of Children 4 (1994), pp. 156-175.

Briere, 1992. J. Briere, Methodological issues in the study of sexual abuse effects. Journal of Consulting and Clinical Psychology 60 (1992), pp. 196-203.

Briggs et al., 1995. K. Briggs, L. Hubbs-Tait, R.E. Culp and M. Blankemeyer, Perceiver bias in expectancies for sexually abused children. Family Relations 44 (1995), pp. 291-298.

Briggs et al., 1994. K. Briggs, L. Hubbs-Tait, R.E. Culp and A.S. Morse, Sexual abuse label: Adults' expectations for children. American Journal of Family Therapy 22 (1994), pp. 304-314.

Bromfield et al., 1988. R. Bromfield, D. Bromfield and B. Weiss, Influence of the sexually abused label on perceptions of a child's failure. Journal of Educational Research 82 (1988), pp. 96-98.

Bromfield et al., 1986. R. Bromfield, J.R. Weisz and I. Messer, Children's judgments and attributions in response to the "mentally retarded" label: A developmental approach. Journal of Abnormal Psychology 95 (1986), pp. 81-87.

Brophy \& Good, 1974. J. Brophy and T. Good, Teacher-student relationships: Causes and consequences. , Holt, Rinehart and Winston, New York (1974).

Browne \& Finkelhor, 1986a. A. Browne and D. Finkelhor, Impact of child sexual abuse: A review of the research. Psychological Bulletin 99 (1986), pp. 66-77.

Browne \& Finkelhor, 1986b. A. Browne and D. Finkelhor, Initial and long-term effects: A review of the research. In: D. Finkelhor, Editor, A sourcebook on child sexual abuse, Sage, Beverly Hills, CA (1986), pp. 143-179.

Bugental et al., 1989. D.B. Bugental, J.B. Blue and M. Cruzcosa, Perceived control over caregiving outcomes: Implications for child abuse. Developmental Psychology 25 (1989), pp. 532-539.

Bugental et al., 1998. D.B. Bugental, C. Johnston, M. New and J. Silvester, Measuring parental attributions: Conceptual and methodological issues. Journal of Family Psychology 12 (1998), pp. 459-480.

Bugental \& Shennum, 1984. D.B. Bugental and W.A. Shennum, "Difficult" children as elicitors and targets of adult communication patterns: An attributional-behavioral transactional analysis. Monotargets of adult communication patterns: An attributional-behavioral transactional analysis.
graphs of the Society for Research in Child Development 291, Serial No. 79 (1984), p. 79.

Cicchetti \& Rogosch, 1997. D. Cicchetti and F.A. Rogosch, The role of self-organization in the promotion of resilience in maltreated children. Development and Psychopathology 9 (1997), pp. 797-815.

Cicchetti \& Toth, 2000. D. Cicchetti and S.L. Toth, Developmental processes in maltreated children. In: D.J. Hansen, Editor, Motivation and child maltreatment 46th Annual Nebraska Symposium on Motivation, , University of Nebraska Press, Lincoln, NE (2000), pp. 85-160.

Cohen \& Mannarino, 1998. J.A. Cohen and A.P. Mannarino, Factors that mediate treatment outcome of sexually abused preschool children: Six- and 12-month follow up. Journal of the American Academy of Child and Adolescent Psychiatry 37 (1998), pp. 44-51.

DeRoma et al., 1997. V.M. DeRoma, D.J. Hansen, A.C. Tishelman and P.D. D'Amico, Influence of information related to child physical abuse on professional ratings of adjustment and prognosis. Child Physical Abuse and Neglect 21 (1997), pp. 295-308.

Eccles \& Wigfield, 1985. J.S. Eccles and A. Wigfield, Teacher expectations and student motivation. In: J. Dusek, Editor, Teacher expectancies, Erlbaum, Hillsdale, NJ (1985), pp. 185-226.

Elashoff \& Snow, 1970. J.D. Elashoff and R.E. Snow, Pygmalion reconsidered. , Charles A. Jones, Worthington, $\mathrm{OH}(1970)$

Elvik, 1994. S.L. Elvik, The effect of the media on child sexual abuse: Commentary. Journal of Child Sexual Abuse 3 (1994), pp. 133-135.

Faller, 1993. K.C. Faller, Child sexual abuse: Intervention and treatment issues. , U.S. Department of Health and Human Services, Washington, DC (1993).

Farina et al., 1968. A. Farina, J. Allen and B. Saul, The role of the stigmatized person in effecting social relationships. Journal of Personality 36 (1968), pp. 69-82.

Farina \& Ring, 1965. A. Farina and K. Ring, The influence of perceived mental illness on interpersonal relations. Journal of Abnormal Psychology 70 (1965), pp. 47-51.

Fink \& Tasman, 1992. P.J. Fink and A. Tasman, Stigma and mental illness. , American Psychiatric Press, Washington, DC (1992).

Fiske \& Taylor, 1984. S.T. Fiske and S.E. Taylor, Social cognition., Addison-Wesley, Reading, MA (1984). 
Foster et al., 1975. G.G. Foster, J.E. Ysseldyke and J.H. Reese, I wouldn't have seen it, if I hadn't believed it. Exceptional Children 41 (1975), pp. 469-473.

Fromuth, 1986. M.E. Fromuth, The relationship of childhood sexual abuse with later psychological and sexual adjustment in a sample of college women. Child Abuse and Neglect 10 (1986), pp. 5-15.

Fromuth \& Burkhart, 1989. M.E. Fromuth and B. Burkhart, Long-term psychological correlates of childhood sexual abuse in two samples of college men. Child Abuse and Neglect 13 (1989), pp. 533-542.

George et al., 1999. W.H. George, J. La Marr, K. Barrett and T. McKinnon, Alcoholic parentage, self-labeling, and endorsement of ACOA-codependent traits. Psychology of Addictive Behaviors 13 (1999), pp. $39-48$.

Gove, 1975. W.R. Gove, The labeling of deviance: Evaluating a perspective., Sage, New York (1975).

Gove, 1980. W.R. Gove, Labeling and mental illness: A critique. In: W.R. Gove, Editor, Labeling deviant behavior, Sage, Beverly Hills, CA (1980), pp. 53-109.

Gove, 1982. W.R. Gove, The current status of the labeling theory of mental illness. In: W.R. Gove, Editor, Deviance and mental illness, Sage, Beverly Hills, CA (1982), pp. 273-300.

Guskin et al., 1975. S.L. Guskin, N.R. Bartel and D.L. MacMillan, Perspective of the labeled child. In: N. Hobbs, Editor, Issues in the classification of children vol. 2, Jossey-Bass, San Francisco, CA (1975), pp. $189-212$.

Hansen et al., 1998. D.J. Hansen, D.B. Hecht and K.T. Futa, Child sexual abuse. In: V.B. Van Hasselt and M. Hersen, Editors, Handbook of psychological treatment protocols for children and adolescents, Erlbaum, Mahwah, NJ (1998), pp. 153-178.

Harris et al., 1992. M.J. Harris, R. Milich, E.M. Corbitt, D.W. Hoover and M. Brady, Self-fulfilling effects of stigmatizing information on children's social interactions. Journal of Personality and Social Psychology 63 (1992), pp. 41-50.

Harter et al., 1988. S. Harter, P.C. Alexander and R.A. Neimeyer, Long-term effects of incestuous child abuse in college women: Social adjustment, social cognition, and family characteristics. Journal of Consulting and Clinical Psychology 56 (1988), pp. 5-8.

Hecht \& Hansen, 1999. D.B. Hecht and D.J. Hansen, Adolescent victims and intergenerational issues in sexual abuse. In: V.B. Van Hasselt and M. Hersen, Editors, Handbook of psychological approaches with violent criminal offenders: Contemporary strategies and issues, Kluwer Academic/Plenum, New York (1999), pp. 303-328.

Hecht \& Hansen, 2001. D.B. Hecht and D.J. Hansen, The environment of child maltreatment: Contextual factors and the development of psychopathology. Aggression and Violent Behavior 6 (2001), pp. 433-457.

Higgins \& McCabe, 1994. D.J. Higgins and M.P. McCabe, The relationship of child sexual abuse and family violence to adult adjustment: Toward an integrated risk-sequelae model. Journal of Sex Research 31 (1994), pp. 255-266.

Hoagwood, 1990. K. Hoagwood, Parental functioning and child sexual abuse. Child and Adolescent Social Work 7 (1990), pp. 377-387.

Jenner, 1990. H. Jenner, The Pygmalion effect: The importance of expectancies. Alcoholism Treatment Quarterly 7 (1990), pp. 127-133.

Jensen, 1980. R. Jensen, Bias in mental testing., Free Press, New York (1980).

Jussim, 1989. L. Jussim, Teacher expectations: Self-fulfilling prophecies, perceptual biases, and accuracy. Journal of Personality and Social Psychology 57 (1989), pp. 469-480.

Jussim, 1991. L. Jussim, Social perception and social reality: A reflection-construction model. Psychological Review 98 (1991), pp. 54-73.

Jussim, 1993. L. Jussim, Accuracy in interpersonal expectations: A reflection-construction analysis of current and classic research. Journal of Personality 61 (1993), pp. 637-668

Jussim \& Eccles, 1992. L. Jussim and J. Eccles, Teacher expectations: II. Construction and reflection of student achievement. Journal of Personality and Social Psychology 63 (1992), pp. 947-961.

Jussim \& Eccles, 1995. L. Jussim and J. Eccles, Naturally occurring interpersonal expectancies. Review of Personality and Social Psychology 15 (1995), pp. 74-108.

Kendall-Tackett et al., 1993. K.A. Kendall-Tackett, L.M. Williams and D. Finkelhor, Impact of sexual abuse on children: A review and synthesis of recent empirical studies. Psychological Bulletin 113 (1993), pp. 164-180.

Kolb \& Jussim, 1994. K.J. Kolb and L. Jussim, Teacher expectations and underachieving gifted children. Roeper Review 17 (1994), pp. 26-30.
Langer \& Abelson, 1974. E.J. Langer and R.P. Abelson, A patient by any other name: Clinician group difference in labeling bias. Journal of Consulting and Clinical Psychology 42 (1974), pp. 4-9.

Leventhal, 1998. J. Leventhal, Epidemiology of sexual abuse of children: Old problems, new directions. Child Abuse and Neglect 22 (1998), pp. 481-491.

Link, 1987. B.G. Link, Understanding labeling effects in the area of mental disorders: An assessment of the effects of expectations of rejection. American Sociological Review 52 (1987), pp. 96-112.

Link et al., 1989. B.G. Link, F.T. Cullen, E. Struening, P. Shrout and B.P. Dohrenwend, A modified labeling theory approach in the area of mental disorders: An empirical assessment. American Sociological Review 54 (1989), pp. 400-423.

Link \& Phelan, 1999a. B.G. Link and J.C. Phelan, The labeling theory of mental disorder: II. The consequences of labeling. In: A.V. Horwitz and T.L. Scheid, Editors, A handbook for the study of mental health: Social context, theories, and systems, Cambridge University Press, New York (1999), pp. 361-376.

Link \& Phelan, 1999b. B.G. Link and J.C. Phelan, Labeling and stigma. In: C.S. Aneshensel and J.C. Phelan, Editors, Handbook of sociology and social research, Kluwer Academic/Plenum, New York (1999), pp. 481-494

Link et al., 1997. B.G. Link, E. Struening, M. Rahav, J.C. Phelan and L. Nuttbrock, On stigma and its consequences: Evidence from a longitudinal study of men with dual diagnoses of mental illness and substance abuse. Journal of Health and Social Behavior 38 (1997), pp. 117-190.

Madon et al., 1997. S. Madon, L. Jussim and J. Eccles, In search of the powerful self-fulfilling prophecy. Journal of Personality and Social Psychology 72 (1997), pp. 791-809.

Mash \& Terdal, 1997. E.J. Mash and L.G. Terdal, Assessment of child and family disturbance: A behavioral-systems approach. In: E.J. Mash and L.G. Terdal, Editors, Assessment of childhood disorders (3rd ed.), Guilford, New York (1997), pp. 3-68.

Merton, 1948. R.K. Merton, The self-fulfilling prophecy. Antioch Review 8 (1948), pp. 193-210.

Milich et al., 1992. R. Milich, C.B. McAninch and M.J. Harris, Effects of stigmatizing information on children's peer relations: Believing is seeing. School Psychology Review 21 (1992), pp. 400-409.

Nash et al., 1993. M.R. Nash, T.L. Hulsey, M.C. Sexton, T.L. Harralson and W. Lambert, Long-term sequelae of childhood sexual abuse: Perceived family environment, psychopathology, and dissociation. Journal of Consulting and Clinical Psychology 61 (1993), pp. 276-283.

National Center on Child Abuse and Neglect, 1996. National Center on Child Abuse and Neglect, Child maltreatment 1994: Reports from the States to the National Center on Child Abuse and Neglect. U.S. Department of Health and Human Services, Washington, DC (1996).

Oates et al., 1994. R.K. Oates, B.I. O'Toole, D.L. Lynch, A. Stern and G. Cooney, Stability and change in outcomes for sexually abused children. Journal of the American Academy of Child and Adolescent Psychiatry 33 (1994), pp. 945-953.

O'Dell, 1997. L. O'Dell, Child sexual abuse and the academic construction of symptomatologies. Feminism and Psychology 7 (1997), pp. 334-339.

Olmstead \& Durham, 1976. D.W. Olmstead and K. Durham, Stability of mental health attitudes: A semantic differential study. Journal of Health and Social Behavior 17 (1976), pp. 35-44

Pain \& Sharpley, 1989. M.D. Pain and C.F. Sharpley, Varying the order in which positive and negative information is presented: Effects on counselors' judgments of clients' mental health. Journal of Couninformation is presented: Effects on co
seling Psychology 36 (1989), pp. 3-7.

Paine \& Hansen, 2002. M.L. Paine and D.J. Hansen, Factors influencing children to self-disclose sexual abuse. Clinical Psychology Review 22 (2002), pp. 271-295.

Pelletier \& Handy, 1986. G. Pelletier and L.C. Handy, Family dysfunction and the psychological impact of child sexual abuse. Canadian Journal of Psychiatry 31 (1986), pp. 407-412.

Polusny \& Follette, 1995. M.A. Polusny and V.M. Follette, Long-term correlates of child sexual abuse: Theory and review of the empirical literature. Applied and Preventative Psychology 4 (1995), pp. 143-166. Abstract

Pope \& Hudson, 1995. H.G. Pope and J.I. Hudson, Does childhood sexual abuse cause adult psychiatric disorders? Essentials of methodology. Journal of Psychiatry and Law (1995, Fall), pp. 363-381.

Rind \& Tromovitch, 1997. B. Rind and P. Tromovitch, A meta-analytic review of findings from national samples on psychological correlates of child sexual abuse. Journal of Sex Research 34 (1997), pp. $237-255$.

Rind et al., 1998. B. Rind, P. Tromovitch and R. Bauserman, A meta-analytic examination of assumed properties of child sexual abuse using college samples. Psychological Bulletin 124 (1998), pp. 22-53. 
Rosenthal \& Jacobson, 1968. R. Rosenthal and L.F. Jacobson, Teacher expectations for the disadvantaged. Scientific American 218 (1968), pp. 19-23.

Rosenthal \& Rubin, 1978. R. Rosenthal and D.B. Rubin, Interpersonal expectancy effects: The first 345 studies. Behavioral and Brain Sciences 3 (1978), pp. 377-415.

Salovey \& Turk, 1991. P. Salovey and D.C. Turk, Clinical judgment and decision-making. In: C.R. Snyder and D.R. Forsyth, Editors, Handbook of social and clinical psychology, Pergamon, New York (1991), pp. $347-416$.

Scheff, 1966. T. Scheff, Being mentally ill: A sociological theory., Aldine, Chicago, IL (1966).

Sedlar et al., 1999. Sedlar, G., Holguin, G., Holm, J. W., Hankla, M., Cohn, L. G., Wan, W. H., \& Hansen, D. J. (1999). Relationship of family functioning with child adjustment after sexual abuse: Implications for assessment and treatment. Poster presented at the 33rd Annual Convention of the Association for for assessment and treatment. Poster presented at the 33rd An

Sibicky \& Dovidio, 1986. M. Sibicky and J.F. Dovidio, Stigma of psychological therapy: Stereotypes, interpersonal reactions, and the self-fulfilling prophecy. Journal of Consulting and Clinical Psychology 33 (1986), pp. 148-154

Smith et al., 1999. A.E. Smith, L. Jussim and J. Eccles, Do self-fulfilling prophecies accumulate, dissipate, or remain stable over time?. Journal of Personality and Social Psychology 77 (1999), pp. 548-565.

Snyder \& Stukas, 1999. M. Snyder and A.A. Stukas, Interpersonal processes: The interplay of cognitive, motivational, and behavioral activities in social interaction. Annual Review of Psychology 50 (1999), pp. 273-303.

Stern et al., 1995. A.E. Stern, D.L. Lynch, R.K. Oates, B.I. O'Toole and G. Cooney, Self esteem, depression, behaviour and family functioning in sexually abused children. Journal of Child Psychology and Psychiatry 36 (1995), pp. 1077-1089.

Stevens-Long, 1973. J. Stevens-Long, The effect of behavioral context on some aspects of adult disciplinary practice and affect. Child Development 44 (1973), pp. 476-484.

Thorndike, 1968. R.L. Thorndike, Review of Pygmalion in the classroom. American Educational Research Journal 5 (1968), pp. 708-711.

Tong et al., 1987. L. Tong, K. Oates and M. McDowell, Personality development following sexual abuse. Child Abuse and Neglect 11 (1987), pp. 371-383.

Tversky \& Kahneman, 1973. A. Tversky and D. Kahneman, Availability: A heuristic for judging frequency probability. Cognitive Psychology 5 (1973), pp. 207-232.

United States Department of Health and Human Services, 2000. United States Department of Health and Human Services, Child Maltreatment 1998: Reports from the States to the National Child Abuse and Neglect Data System. , U.S. Government Printing Office, Washington, DC (2000).

Watkins \& Bentovim, 1992. B. Watkins and A. Bentovim, The sexual abuse of male children and adolescents: A review of current research. Journal of Child Psychology and Psychiatry 33 (1992), pp. $197-248$.

Wolfe \& Birt, 1997. V.V. Wolfe and J. Birt, Child sexual abuse. In: E.J. Mash and L.G. Terdal, Editors, Assessment of childhood disorders (3rd ed.),, Guilford, New York (1997), pp. 569-623.

Yates et al., 1978. B.T. Yates, S.B. Klein and W.G. Haven, Psychological nosology and mnemonic reconstruction: Effects of diagnostic labels on observers' recall of positive and negative behavior frequencies. Cognitive Therapy and Research 2 (1978), pp. 377-387. 